\title{
Biopolítica y necropolítica: ¿constitutivos u opuestos?
}

\section{Biopolitics and necropolitics: opposite or constitutive?}

doi: http://dx.doi.org/10.32870/espiral.v25i73.7017

Ariadna Estévez

\begin{abstract}
Resumen
Este artículo busca responder la pregunta de si la polarización en los objetivos de la biopolítica (administrar la vida y construir estilos de vida) y la necropolítica (administrar la muerte y destruir hábitats y pueblos) hace a estos conceptos opuestos o, por el contrario, si estos señalan una relación dialéctica de construcción mutua en fenómenos como la migración. Para responder a dicha interrogante, el artículo primero examina la biopolítica en el trabajo de Michel Foucault y cómo este ha sido retomado en el análisis de la migración contemporánea. Luego, describe la necropolítica a partir del trabajo de Achille Mbembe y cómo ha sido retomado para identificar causas de migración forzada y trato racista a migrantes. Finalmente, se hace una revisión de literatura de estudios biopolíticos y necropolíticos en el contexto de la migración internacional.
\end{abstract}

Palabras clave: biopolítica, necropolítica, migración, Foucault, Mbembe.

\begin{abstract}
This article searches for respond to the question whether biopolitic's objective (to manage life and construct lifestyles) and necropolitic's objective (to administrate death and destroy habitats and peoples), polarized, make both concepts opposites, or on the contrary, if they indicate a dialectical relationship and mutual construction in phenomena such as migration. To answer the question, the article first examines biopolitics in the work of Michel Foucault and seeks how it has been taken up in the analysis of contemporary migration. The paper then describes necropolitics in the work of Achille Mbembe, and how it has been taken up to identify the causes of forced migration and racism against migrants. Finally, it reviews the literature on biopolitical and necropolitical studies in the context of international migration.
\end{abstract}

Keywords: Biopolitics, necropolitics, migration, Foucault, Mbembe.

- Profesora-Investigadora del Centro de Investigaciones sobre América del Norte (CISAN) de la Universidad Nacional Autónoma de México (UNAM), México. ORCID: http://orcid.org/00000002-586I-3956_aestevez@unam.mx

Fecha de recepción: 29 de noviembre de 2017. Fecha de aceptación: 10 de abril de 2018 


\section{Introducción}

Mucho del análisis social y político actual parece girar en torno a dos conceptos que a veces, a su vez, parecen ocuparse de cosas distintas: la biopolítica y la necropolítica. El primero se refiere al poder sobre la vida a través de tecnologías de dominación tales como leyes y políticas públicas para la gestión de la vida humana en tanto especie, para garantizar que la población, la sociedad en su dimensión existencial y biológica, mantenga su statu quo racial. El segundo se refiere al poder de dar muerte con tecnologías de explotación y destrucción de cuerpos tales como la masacre, el feminicidio, la ejecución, la esclavitud, el comercio sexual y la desaparición forzada, así como los dispositivos legaladministrativos que ordenan y sistematizan los efectos o las causas de las políticas de muerte.

El presente artículo busca dar una explicación de cada concepto, y discernir si estos conceptos son excluyentes el uno del otro. Se propone la hipótesis teórica de que en realidad son categorías constitutivas, es decir, se construyen la una a la otra, en el entendido de que la aplicación previa de necropolíticas que hayan destruido hábitats, cuerpos, modos de vida y sectores económicos hace posible la gestión de la vida a través de inoculaciones como la de la figura del asilo o la migración legal.

Para alcanzar estos objetivos, primero se discutirá el biopoder como lo entiende Michel Foucault. Luego, se describirá el trabajo de los filósofos italianos Giorgio Agamben y Roberto Esposito, quienes debaten el papel de la biopolítica a través de la figura del refugiado y la migración en el mundo actual. Posteriormente, se discutirá la interpretación decolonial del biopoder para formular el necropoder como una expresión de la regulación de la muerte en el tercer mundo, como lo teorizó Achille Mbembe. Acto seguido, se hablará del rol que juegan ambos conceptos en 
la gubernamentalidad neoliberal y sus dispositivos, así como el capitalismo más corrosivo de diferentes formas de vida. Finalmente, se expondrán la migración y el asilo como momentos en los que biopolítica y necropolítica son inexorablemente constitutivos.

\section{Biopolítica: la regulación de la vida}

Michel Foucault no hizo una teoría del poder, pero sí aventuró una filosofía analítica del poder, que no intenta definirlo, sino establecer cómo funciona y cómo somete a los sujetos (Castro, 2004, p. 2014). Este trabajo analítico repara en los sistemas de diferenciación, las modalidades instrumentales y las formas de institucionalización del poder. Para esta filosofía, el poder consiste en conducir conductas, es decir, no actúa sobre las personas, sino sobre sus acciones, induciéndolas, facilitándolas, dificultándolas, limitándolas o impidiéndolas. De este modo, las relaciones de poder se vuelven de dominación cuando son bloqueadas con técnicas que permiten dominar la conducta de otros.

También desde esta filosofía, el vehículo ideal del poder es el discurso, el cual es el conjunto de elementos o bloques de tácticas en las relaciones de fuerza, los cuales determinan subjetividades y tienen efectos de verdad, es decir, establecen subjetividades, objetos y saberes que dividen lo falso de lo verdadero. La división entre falso y verdadero genera formas de exclusión discursiva que se vuelven un sistema, es decir, de carácter histórico, modificable e institucionalmente coercitivo.

Para crear estos efectos de verdad, los discursos se apoyan en otros discursos verdaderos y se producen y distribuyen bajo el control de grandes aparatos políticos y económicos que permiten determinar las distinciones entre enunciados falsos y verdaderos, las formas en que se sancionan unos y otros, las técnicas y los procedimientos para la obtención 
de la verdad, y el estatus de aquellos sujetos que tienen la función de decir lo que funciona como verdadero. Estos aparatos políticos y económicos que permiten establecer la división entre lo falso y lo verdadero constituyen lo que Foucault denominó dispositivo, y que será explicado más adelante al hablar de la gubernamentalidad neoliberal (Foucault, 2004).

Foucault encontró tres tipos de poder que emergen en contextos históricos determinados, pero que no se reemplazan uno con el otro, sino que se superponen: el poder soberano, el poder disciplinario y el biopoder (Foucault, 2000, 2004; Foucault, Senellart, y Davidson, 2007). El poder político en Europa se ha desarrollado en un continuum en el que los diferentes tipos de poder operan al unísono y de forma complementaria. El poder disciplinario no sustituye al soberano, sino que lo incorpora y lo lleva a otro nivel, centrándose en los cuerpos individuales como su objeto para disciplinarlos y hacerlos dóciles. Se disciplinan los cuerpos para vigilarlos, entrenarlos, utilizarlos y castigarlos en función de la productividad económica. El uso de las disciplinas del saber y las instituciones por parte del poder disciplinario es lo que Foucault llamó anatomopolítica.

El biopoder, por su parte, modifica el objetivo soberano del poder disciplinario de dejar vivir y hacer morir y lo invierte: en lugar de dejar vivir y hacer morir, ahora el poder tiene el objetivo de hacer vivir y dejar morir. El biopoder se centra en los procesos que son específicos de la propia vida, como el nacimiento, la muerte, la reproducción, la migración y la enfermedad, así que también son diferentes la racionalidad, dispositivos, estrategias y luchas o resistencias que genera (Castro, 2004, p. 2014; Foucault, 2006a, 2006b). En la biopolítica, el objetivo ya no es el cuerpo individual, sino la regulación de la población como cuerpo político. Como lo dice Foucault, se trata de un asesinato indirecto, porque sin necesidad de que poblaciones enteras sean matadas 
intencionalmente, estas mueren como consecuencia de que el Estado no haga algo por ellas. El campo biológico controlado por el biopoder se fragmenta en una jerarquía de razas, y los que están en la parte inferior son los que son abandonados para morir (Foucault, 2006a, 2006b).

En el biopoder, las tecnologías que se usan también son diferentes: medicina, estadística, control natal, política pública, o cualquier cosa encaminada a controlar y regular la población (Foucault, 2000, 2006a, 2006b; Foucault, Senellart, y Davidson, 2007). A aquellos que amenazan la sobrevivencia de la mayoría se les deja morir al ser omitidos como objetos de política pública y otras tecnologías, como sucede, por ejemplo, con la negación de servicios de salud primaria a migrantes indocumentados. Toda vez que este tipo de poder se refiere a "una masa de seres vivientes y coexistentes que tienen particularidades biológicas y patológicas y que por ello se colocan bajo un conocimiento y tecnologías específicas" (Foucault, 1997, p. 71), Foucault se refirió a esto como biopolítica. La biopolítica, dice Foucault, es lo que caracteriza la política moderna desde el siglo XVI (Foucault, 2004).

Por esta razón, la regulación de la migración a través de una biopolítica que tiene como fin definir a quién se le permite entrar y permanecer en un territorio determinado es central a la gubernamentalidad neoliberal, y constituye un tema fundamental del análisis del biopoder. Según Campesi (2012), en términos generales, el discurso biopolítico -en concreto el de securitización- construye a los migrantes de tres diferentes maneras. En la primera, los migrantes son vistos como actores transnacionales clandestinos que imponen amenazas estratégicas a Estados receptores, lo cual ayuda a explicar por qué es necesario el aseguramiento de las fronteras. En la segunda, los migrantes representan una amenaza política al balance cultural, étnico y social, lo cual lleva a racismo y política de identidades radical. 
En la tercera, los migrantes son competidores económicos injustos en los mercados laborales que sacan provecho de los beneficios del Estado de bienestar en los países de occidente (Campesi, 2012).

\section{Agamben: Estado de excepción, nuda vida y homo sacer}

En los estudios biopolíticos de la migración, los intereses de investigación tienen que ver con las dos primeras construcciones señaladas -los migrantes como clandestinos y como amenaza cultural-, y se enfocan en analizar las tecnologías y dispositivos de poder que securitizan fronteras y regulan la amenaza cultural. Las investigaciones que analizan las tecnologías de aseguramiento de fronteras han recurrido a la lectura que ha hecho Giorgio Agamben de Foucault, en particular respecto al lugar fundamental que tiene en la biopolítica la categoría schmittiana del Estado de excepción y el papel de lo que Agamben denomina nuda vida en el sujeto central de la biopolítica, que él ha conceptualizado como el homo sacer.

Mientras que Carl Schmitt dijo que el Estado de excepción se refiere a medidas extraordinarias dentro de una democracia durante un periodo de crisis - una especie de tierra de nadie existente entre la ley y la política-, Agamben dice que en las democracias actuales el Estado de excepción ya no es una excepción sino la regla. Ahora vivimos en un estado de guerra civil legal en la que la vida está subordinada al poder del Estado y sólo está presente en la ley a través de su exclusión. Como ya se dijo antes, en el Estado de excepción la nuda vida y el homo sacer son de suma importancia (Agamben, 2001, 2004).

Para Agamben, la nuda vida es la reducción de la vida humana a su estatus biológico, y el autor la equipara con el zoé de los griegos, es decir, la vida simple y mundana, opuesta y separada del bios, la vida política. Agamben 
encuentra el origen de la inclusión de zoé en el poder político en la figura del homo sacer, el cual es una figura políticojurídica de la Antigüedad que refiere a la persona que ha sido juzgada y acusada de un crimen, y a la que no se permite sacrificar, pero que quien la mate no será acusado de homicidio. Esta persona, que queda en la total desprotección de la ley, se encuentra incluida en ella únicamente por su exclusión. La nuda vida del homo sacer es sujeto de política sólo a través de la excepción. Para Agamben, el homo sacer como persona que puede ser asesinada pero no sacrificada es la primera figura que establece el poder biopolítico del soberano porque subjetiviza la nuda vida no a través de su inclusión en el orden jurídico, sino de su exclusión (Agamben, 1998).

Agamben propone que el homo sacer de nuestro tiempo, la persona que hoy en día tiene una vida de exclusión jurídica y política, sujeta a violencia y vulnerabilidad, es el refugiado. La figura del refugiado representa un quiebre en la continuidad que hay entre hombre y ciudadano. El refugiado establece la división entre nacimiento y nacionalidad, y con ello la persona que tiene su estatus no posee nada más que derechos humanos. Para Agamben,

Al poner a la luz la diferencia entre nacimiento y nación, el refugiado hace que el presupuesto secreto del dominio político -la nuda vidaaparezca momentáneamente en ese dominio. En ese sentido, el refugiado es el verdadero "hombre de derechos" que sugiere Arendt, la primera y única real aparición de derechos fuera de la ficción del ciudadano que siempre los cubre (Agamben, 1998, pp. 132-133).

Para Agamben, el refugiado es la clara muestra de la despolitización de la esfera de su protección, es decir, del ámbito de lo humanitario. Por un lado, los Estados se muestran interesados en la vida natural y distinguen entre una vida auténtica y una carente de todo valor político, y por el otro, 
los derechos humanos se usan fuera del contexto de la ciudadanía para la protección de la nuda vida, que está cada vez más en los márgenes de los Estados nación (Agamben, 1998, pp. 132-133).

Por estas características, para Agamben el refugiado es la mejor representación del homo sacer contemporáneo, es decir, aquel que se encuentra incluido en lo político y lo jurídico únicamente a través de su exclusión, por lo cual puede ser asesinado sin que ello se considere un asesinato. El refugiado encarna la nuda vida, una vida humana simplemente biológica, sin valor político, por lo que su protección se ha sustraído del campo político y se ha dejado en el campo estrictamente humanitario. En consecuencia, los campos de detención de refugiados son los nuevos campos de concentración, que expresan la sofisticación totalitaria de la biopolítica contemporánea (Agamben, 1998).

La idea del refugiado como una expresión del homo sacer contemporáneo ha sido sumamente influyente en los estudios sobre el estatus vulnerable de los refugiados en Europa y América del Norte (Darling, 2009; Edkins y Pin-Fat, 2005; Muller, 2004; Owens, 2009; Tyler, 2010; Zylinska, 2004). Sin embargo, también ha sido objeto de críticas por su nihilismo y por entender lo político desde una perspectiva que cancela toda posibilidad de resistencia y emancipación, especialmente en el caso de los refugiados (Juniper, 2006; Owens, 2009), pero también en lo general (Laclau, 2008). Asimismo, Agamben ha sido criticado por universalizar la idea de la nuda vida sin atender la argumentación de Foucault sobre el papel que tiene el racismo en el ejercicio del biopoder (Butler, 2006). Para Estévez (2012a), la idea del refugiado como una entidad meramente biológica sin vínculo a lo político se parece a un argumento sin sustento si por político se entiende la relación amigo-enemigo que define el propio Schmitt: hoy en día no hay nada más político que el cuerpo del refugiado. 


\section{Esposito: inmunidad y comunidad}

Por otra parte, los estudios que analizan las tecnologías y dispositivos para la regulación de la amenaza cultural se apoyan en la ruta biopolítica propuesta por Roberto Esposito (2005), quien ve la regulación poblacional como una suerte de inmunización contra virus raciales y culturales. Esposito hace una analogía entre la política de la vida y el sistema inmune del cuerpo humano, asegurando que este lucha contra amenazas exógenas de la misma forma que el biopoder lucha contra formas de vida que amenazan a la mayoría. Esposito distingue entre política sobre la vida y política de la vida. La regulación y control de la migración obedecen a una política sobre la vida que opera como un sistema inmune que defiende el cuerpo -la población- a través de medios negativos que eventualmente se vuelven contra el sistema mismo.

Como sabemos, en medicina la inmunización requiere de la introducción de una dosis no letal del patógeno al cuerpo, lo cual crea anticuerpos y eventualmente excluye al patógeno. La importancia de esto para la política y la migración es que el patógeno no se elimina del cuerpo -la sociedad- prohibiendo la migración como conjunto, sino implementando la política que crea las categorías que niegan al patógeno, tales como legalidad, normas de asilo y ciudadanía, las cuales dan cabida al migrante económico, el migrante ilegal o el solicitante de asilo falso, que permiten la exclusión. El cambio progresivo, o inmunización de la comunidad, se logra introduciendo reformas legales, política pública y estrategias legales como el asilo, las cuales crean y reafirman categorías que niegan nuevas formas de migración (Esposito, 2005).

Para Esposito, un Estado soberano construye su política migratoria como una defensa contra la amenaza de migrantes peligrosos y no bienvenidos, esos que amenazan su 
seguridad y cultura. Los inmigrantes y solicitantes de asilo son un patógeno que hay que introducir en dosis muy pequeñas para inmunizar el sistema e impedir el contagio racial y cultural. La inmunización es, pues, la política migratoria y el uso táctico del dispositivo de asilo. Así pues, se puede decir que en la biopolítica de Esposito (2005) el dispositivo migratorio es una forma de inmunización contra la amenaza de grupos patógenos (migrantes económicos y solicitantes de asilo), ya que no niega la migración del todo y en sí misma, sino que implementa estrategias discursivas mediante diversas tácticas que a su vez se apoyan en tecnologías varias que tienen como fin impedir que el número de personas aceptadas rebase los límites de una inmunización eficiente.

\section{Necropolítica: administración de la muerte}

Diversos teóricos de África, América Latina y Europa del Este han destacado que el biopoder no funciona igual en todas partes, y que es insuficiente para explicar los objetivos de las relaciones de poder en el tercer mundo, donde la violencia criminal y del Estado revelan que el objetivo es la regulación no de la vida, sino de la muerte. En otras palabras, en el tercer mundo, en vez de biopolítica hay una necropolítica (Gržinić, 2010; Gržinić y Tatlić, 2014; Mbembe, 2011; Valencia, 2010; Valverde Gefaell, 2016). Para estos teóricos, la biopolítica es un punto de partida fundamental para el análisis de las relaciones de dominación, pero en el contexto del tercer mundo resulta insuficiente porque los dispositivos, técnicas, prácticas y estrategias en las relaciones de dominación tienen efectos muy radicales, como las consecuencias de la llamada guerra contra el narcotráfico en México. No se trata de decir que biopoder y necropoder se contrapongan, sino que es necesario situar los fines de cada uno -regulación de la vida y de la muerte, respectiva-

\section{8}


mente- para ubicar con precisión cómo sus dispositivos y estrategias se entrelazan.

Achille Mbembe (2011) es a quien se le atribuye el concepto de necropolítica. Él sostiene que la biopolítica no es suficiente para entender cómo la vida se subordina al poder de la muerte en África. Afirma que la proliferación de armas y la existencia de mundos de muerte -lugares donde la gente se encuentra tan marginada que en realidad vive como muerto viviente- son un indicador de que existe una política de la muerte (necropolítica) en lugar de una política de la vida (biopolítica) como la entiende Foucault (Mbembe, 2011).

Mbembe examina cómo el derecho soberano de matar se reformula en las sociedades donde el Estado de excepción tal como lo propone Agamben es permanente. Según Mbembe, en un estado sistemático de emergencia, el poder refiere y apela constantemente a la excepción y a una idea ficticia del enemigo. Mbembe afirma que el esclavismo y el colonialismo en África y en Palestina han sido el producto de la política de la vida, aunque estas tragedias humanas de la modernidad han sido ignoradas en las lecturas históricas del biopoder.

Con el fin de analizar la necropolítica en los conflictos contemporáneos, Mbembe se basa en el estudio de las guerras de la era de la globalización que hace Zygmunt Bauman (Bauman, 2001) para argumentar que las operaciones militares y el derecho de matar no son ya prerrogativas exclusivas del Estado, y que el Ejército regular no es ya el único medio para ejecutar el derecho de matar. Las milicias urbanas, los ejércitos privados y las policías de seguridad privada tienen también acceso a las técnicas y prácticas de muerte. La proliferación de entidades necroempoderadas, junto con el acceso generalizado a tecnologías sofisticadas de destrucción y las consecuencias de las políticas socioeconómicas neoliberales, hacen que los campos de concentración, los guetos y las plantaciones se conviertan en aparatos dis- 
ciplinarios innecesarios porque son fácilmente sustituidos por la masacre, una tecnología del necropoder que puede ejecutarse en cualquier lugar y en cualquier momento (Mbembe, 2011).

La lectura africana del biopoder de Foucault de Mbembe ha influido fuertemente a otros estudiosos que escriben, desde la perspectiva de la periferia intelectual, sobre el papel de la gubernamentalidad como dispositivo del poder de administrar muerte. Por ejemplo, con base en Mbembe, la filósofa y crítica de arte eslovena Marina Gržinić (2010) dice que la biopolítica es la conceptualización específica de la gubernamentalidad neoliberal exclusivamente reservada para el primer mundo, pues para el segundo mundo (el de los países exsocialistas) y el tercer mundo (Asia, África y América Latina) la regulación de la vida se ha transformado en la regulación de la muerte dentro de condiciones extremas producidas por el capital. La vida es regulada a través de la perspectiva de la muerte y transformada en regulación de la muerte, en una mera existencia debajo del nivel de vida más básico (Gržinić y Tatlić, 2014).

Para Gržinić, hay diferencias abismales entre biopolítica y necropolítica. Con la primera, se controla la vida para garantizar un buen estilo de vida, mientras que con la segunda se abandona la estructura de regulación vital -salud, educación, formación de capital humano- y lo que se controla, usa y capitaliza es la muerte a través de la máquina de guerra. La regulación de la vida en el primer mundo capitalista produce estilos de vida, y el paso de la biopolítica a la necropolítica implica un cambio cualitativo en la concepción de la muerte, que es doble: muerte real por empobrecimiento masivo, y muerte simbólica por las intervenciones del capitalismo en lo social, lo político y lo simbólico. No obstante, en el primer mundo también hay rastros de necropolítica que se invisibilizan y esconden, como el desmantelamiento de la política social para ciu- 
dadanos y la explotación, deportación y marginación de migrantes del segundo y tercer mundo en el espacio de Schengen (Gržinić y Tatlić, 2014).

Por su parte, la filósofa tijuanense Valencia (2010) coincide con Mbembe y Gržinić en su reinterpretación y radicalización de la biopolítica de Foucault y, como ellos, cree que la muerte, más que la vida, se encuentra al centro de la biopolítica, transformándola en necropolítica. Sin embargo, Valencia se desmarca de esas perspectivas diciendo que en el tercer mundo no es suficiente con incorporar al análisis el impacto mortal del neoliberalismo y de las actividades de las entidades privadas necroempoderadas, sino que el análisis tiene que ser geopolítica y contextualmente específico. En su caso, ella reflexiona sobre la necropolítica en sociedades simultáneamente empobrecidas e hiperconsumistas como las de las ciudades fronterizas de México, donde la violencia extrema y el hiperconsumo son elementos estructurantes en la construcción de subjetividades disidentes, aunque ilegítimas, que resisten el poder del Estado (Valencia, 2010).

También, Valencia afirma que el biopoder controla los procesos vitales, y que las exigencias capitalistas han transformado en mercancías la vida y todos sus procesos asociados, como la muerte. En las sociedades hiperconsumistas, los cuerpos se convierten en una mercancía, y su cuidado, conservación, libertad e integridad son productos relacionados. Como mercancía, la vida es más valiosa si se encuentra amenazada, secuestrada y torturada (Valencia, 2010). Para la filósofa, las corporaciones de las drogas ilegales ejercen un poder de opresión análogo al del Estado y se han convertido en un Estado paralelo que reconfigura la biopolítica y utiliza técnicas que Valencia denomina necroprácticas -acciones radicales dirigidas a infringir dolor, sufrimiento y muerte, por ejemplo, el asesinato, la tortura y el secuestro- para aprovechar, conservar y lucrar con el poder de hacer morir. 
Al igual que el Estado legítimo, su contraparte criminal pretende tener el control sobre el territorio, la seguridad y la población, es decir, gobernar a través de la explotación de los recursos nacionales, la venta de seguridad privada y la población. Controla los cuerpos de la población y los hace mercancías de intercambio o consumidores de los bienes ofertados en el narcomercado (Valencia, 2010).

Como la biopolítica, la necropolítica sirve para analizar procesos migratorios desde la perspectiva de dejar morir de acuerdo con raza, género y estatus legal (Gržinić y Tatlić, 2014). La propia Gržinić ha desarrollado su idea de necropolítica en el segundo mundo considerando la migración cuando habla de la racialización como un proceso del capital. Ella propone que la racialización sea un proceso de diferenciación entre los ciudadanos -por nacimiento y adquisición-, los no ciudadanos -refugiados, solicitantes de asilo-, y los migrantes documentados en Europa. Todos son violentados, pero también discriminados de forma diferente pues los mercados laborales imponen procesos violentos de selección entre migrantes de acuerdo a la raza, la clase y el género. Hasta abajo, están aquellos que solamente alcanzan a entrar a Europa y obtener la ciudadanía cuando han muerto (Gržinić y Tatlić, 2014).

John Round e Irina Kuznetsova coinciden con Gržinić en que en Europa el necropoder, más que el biopoder, es lo indicado para analizar las tecnologías que sujetan las vidas de los migrantes irregulares, pues son considerados desechables y nadie se preocupa por garantizarles servicios de salud, seguridad laboral o educación. Los autores creen que es imperativo teorizar la muerte a la que son expuestos, y optan por desarrollar un marco en torno a la idea de dejar morir para exponer cómo los migrantes son criminalizados y vistos como portadores de enfermedades, aunque no se les proporciona ayuda alguna (Round y Kuznetsova, 2016). 
Por su parte, Henao Castro (2016) encuentra el lugar de la necropolítica en la frontera, donde se juntan los dispositivos biopolíticos con los propiamente necropolíticos, y se enfoca en el dispositivo necropolítico de desechabilidad, que convierte en desechables a los migrantes irregulares apenas cruzan las fronteras, que tienen tres características: militarización, precariedad social y producción de mundos de muerte (Henao Castro, 2016).

\section{5. ¿Capitalismo o neoliberalismo?}

En el corazón de los marcos interpretativos de la regulación de la vida y la muerte, se encuentran las relaciones de producción. Actualmente, se conduce la vida hacia su expansión, precariedad o extinción con el objeto de incidir en las relaciones de reproducción económica del capitalismo. No obstante, esta conducción puede ser analizada a través del funcionamiento de su discurso político-económico, el neoliberalismo, o de sus actividades y sectores de extracción y acumulación, el capitalismo en su dimensión material y económica.

Los estudios biopolíticos parecieran identificarse más con la gubernamentalidad neoliberal de los procesos de regulación de la vida, mientras que los estudios necropolíticos se enfocan en las actividades y nuevos sectores de extracción para la acumulación por desposesión, como lo llamó Harvey (2004). Al final, ambas perspectivas ven el problema del capitalismo actual, el del discurso neoliberal, como la piedra angular de la regulación de los procesos de vida y muerte, pero la preferencia epistemológica de una y otra tiene que ver con el espacio en el que se implementa cada una (Harvey, 2004). 


\section{I La gubernamentalidad neoliberal}

\section{y la gubernamentalización del Estado}

Muchos de los estudios del biopoder se enfocan en la gubernamentalidad neoliberal. En el marco foucaultiano, la palabra gobierno no se refiere a la institución de Gobierno sino a "una actividad encaminada a conducir a los individuos a lo largo de sus vidas poniéndolos bajo la autoridad de una guía responsable de lo que hacen y lo que pasa con ellos" (Foucault, 1997, p. 67).

Para Foucault, las técnicas de gobierno no son exclusivas del Estado, pues constituyen el conjunto de acciones sobre las acciones posibles de otros sujetos, o las acciones de los sujetos ejercidas sobre sí mismos para dominar placeres o deseos: "Gobierno de niños, gobierno de almas y conciencias, gobierno de una casa, de un estado, o de uno mismo" (Foucault, 1997, p. 81). Las técnicas de gobierno de sí-regulación de los propios deseos y cuerpo, el autocuidado- y de poder -normas que conducen a fines de dominación- constituyen lo que Foucault llamó gubernamentalidad, es decir, la racionalidad del neoliberalismo en la biopolítica (Foucault, 1997, p. 67).

Según el estudio genealógico de Foucault, el neoliberalismo se opone a la intervención estatal y su expansión burocrática en nombre de la libertad económica porque atenta contra los derechos individuales. El objetivo central del neoliberalismo es aplicar el discurso económico -conceptos, objetos, lógicas y lenguaje- al análisis social, borrando las diferencias entre los dos campos. El modelo de racionalidad económica se usa para justificar y limitar la acción gubernamental. Al mismo tiempo, la gubernamentalidad neoliberal crea, por su énfasis en las técnicas de dominación y de control de sí, un individuo autocontrolado e interesado en la maximización de su propia función económica: el homo economicus. 
El Estado no es de ninguna manera el único agente de la gubernamentalidad neoliberal, pero como señala Castro (2004), Foucault sugirió que en el desarrollo del liberalismo y el neoliberalismo el Estado se erigió como la objetivación de diversas prácticas de gubernamentalidad, de la misma forma que la locura surgió de prácticas disciplinarias y médicas (Castro, 2004). No se trata, dice Castro, del gobierno estatal, sino de la gubernamentalización del Estado. O como lo sugirió el propio Foucault:

Es un hecho indudable que el Estado en las sociedades contemporáneas no es sólo una de las formas o uno de los lugares -aunque fuera el más importante- de ejercicio del poder, sino que de cierta manera todas las otras formas de relación de poder se refieren a él. Pero no es porque cada uno se derive de él. Es más bien porque se ha producido una estatización continua de las relaciones de poder (si bien no adquirió la misma forma en el orden pedagógico, judicial, económico, familiar). Haciendo referencia aquí al sentido restringido de la palabra gobierno, podría decirse que las relaciones de poder se gubernamentalizaron' progresivamente, es decir, se elaboraron, racionalizaron, centralizaron bajo la forma o bajo los auspicios de instituciones estatales (Foucault, 1988, pp. 18-19).

El Estado gubernamentalizado incluye políticas públicas, las mediciones y la desviación de servicios hacia el ámbito corporativo. El Estado se vuelve un administrador de negocios a cargo de universalizar la competencia e inventar sistemas para la acción individual y social, mismos que se rigen por las leyes del mercado. De esta forma, la economía deja de ser sólo un área de la vida humana y pasa a cubrir todas sus áreas.

Universalizar la economía sirve para entender lo social y evaluar el desempeño estatal en términos económicos, esto 
con el fin de subordinar todas las esferas a las dinámicas del mercado (Foucault, 2004). Para el neoliberalismo, el Estado no define o evalúa la libertad del mercado, sino que el mercado es el principio regulador del Estado, es decir, el mercado controla al Estado y no al revés. Además, no existe tal cosa como la libertad natural que el Estado tenga que respetar: se crea una libertad artificial, la libertad de los individuos económicamente racionales (Foucault, 2006a).

Por esta razón, los Estados neoliberales se han convertido en Estados gerenciales que ya no sólo controlan el comportamiento individual a través de la disciplina, sino que también regulan y administran el crecimiento y la mortandad de la población para la reproducción de sí misma a través de técnicas de autocuidado, es decir, de desplazar al individuo la responsabilidad sobre su propia salud, educación y todo aquello que incide en la reproducción del capital humano que cada individuo posee. Para lograr desplazar sus obligaciones sociales al individuo, el Estado neoliberal echa mano de dos tecnologías de poder: la norma y la política pública.

Así definida, la gubernamentalización el Estado podría tomarse como un efecto directo de la gubernamentalidad neoliberal. Análogamente, como dice Valencia (2010), podría constituir una apropiación criminal de los elementos fundamentales de la gubernamentalidad: territorio, seguridad y población. Sus políticas pueden ser políticas de víctimas, drogas, cohesión social, migración o salud, entre otras, orientadas a fortalecer el mercado, conducir la conducta de la población y mantener niveles de impunidad que permitan la reproducción del capital que lo sostiene, que en muchos casos tiene participación criminal. La gubernamentalización del Estado a través de la privatización criminal de la violencia y del dominio del capital criminal es lo que se llamará la gubernamentalización necropolítica del Estado. 


\subsection{Los dispositivos}

En el neoliberalismo, se ha tomado una "importancia creciente [...] por el juego de la norma a expensas del sistema jurídico de la ley" (Castro, 2004, p. 219): no es que

la ley desaparezca o que las instituciones de justicia tiendan a desaparecer, sino que la ley funciona cada vez más como una norma y que la institución judicial se integra más y más a un continuum de dispositivos (médicos, administrativos) cuyas funciones son sobre todo reguladoras (Castro, 2004, p. 219).

Asimismo, el Estado neoliberal implementa diferentes tipos de política pública a través de sus diferentes dispositivos. Esta se define como la toma de decisiones del Estado para modificar u orientar la acción social y que toma la forma de elementos legales, políticos y técnicos basados en el conocimiento social (Guendel, 2009, p. 3). En el neoliberalismo, se espera que la política pública regule la salud y el crecimiento de la población (Foucault, 1997, pp. 70-71), pero no con intervención estatal directa, como ocurría en el Estado de bienestar, sino con políticas encaminadas a que el individuo se haga cargo de sí mismo, o en términos neoliberales, encaminadas a invertir en su propio capital humano.

El dispositivo en la filosofía del poder de Foucault es la red de relaciones sociales construidas en torno a un discurso: instituciones, leyes, políticas, disciplinas, declaraciones científicas y filosóficas, conceptos y posiciones morales, que tienen la función específica de mantener el poder. En la era de la gubernamentalidad neoliberal, los dispositivos se caracterizan por ser incluyentes, ya que tienden a incluir cada vez más elementos; permisivos, pues pueden ser añadidos; y excluyentes, pues eliminan aquello a lo que están dirigidos (Foucault, 2006b, pp. 66-67).

Agamben ha ampliado el concepto de dispositivo diciendo que 
Generalizando la ulteriormente ya amplísima clase de los dispositivos foucaultianos, llamaré literalmente dispositivo a cualquier cosa que tenga de algún modo la capacidad de capturar, orientar, determinar, interceptar, modelar, controlar y asegurar los gestos, las conductas, las opiniones y los discursos de los seres vivientes (Agamben, 2009, p. 14).

Los dispositivos conjuntan diversas tecnologías regulatorias, tales como oficinas gubernamentales, consejos, cortes, oficinas legales, organizaciones de la sociedad civil y la ley misma. Comúnmente, la ley pertenece a los poderes soberano y disciplinario: mientras que el primero resulta en códigos legales, el segundo implementa estos códigos de forma institucional (Foucault, Senellart, y Davidson, 2007).

No obstante, existe un uso estratégico de la ley en la gubernamentalidad neoliberal, por lo que las normas se vuelven más importantes que el sistema judicial mismo. Esto no significa que la ley o sus instituciones tienden a desaparecer, sino que la ley sirve cada vez más como norma -con el objetivo de imponer conformidad y homogenizar-, y que sus instituciones están más integradas en la gubernamentalidad neoliberal a través de un continuum de dispositivos con funciones reguladoras.

Los análisis de la gubernamentalidad de la migración se enfocan en cómo las instituciones, las leyes, los centros de detención, las cortes, las organizaciones no gubernamentales y otras burocracias constituyen un dispositivo para administrar y gestionar la vida de los migrantes. Estos análisis estudian las diferentes estrategias y tácticas a través de las cuales los migrantes son administrados, construidos y finalmente expulsados de un país. El discurso de asilo es una estrategia en la que la ley juega un papel fundamental para operativizar la exclusión. 


\subsection{Capitalismos necropolíticos}

El capitalismo, o más bien dicho, las formas radicalmente corrosivas de capitalismo son fundamentales en la necropolítica. Como sabemos, en las teorizaciones recientes sobre el capitalismo, se encuentra una serie de adjetivaciones que reflejan la complejidad de definir aquello que Karl Marx discutió de manera profunda, pero sin incluir la muerte al establecer su ontología.

La inconmensurabilidad del capitalismo neoliberal y su ethos de muerte se encuentran desarrollados en ideas como el capitalismo zombi (Harman, 2009), que con base en los conceptos originales de Marx se enfoca en la capacidad destructiva del capital y su poder para ponernos en contra de nosotros mismos; el capitalismo gánster (Woodiwiss, 2005), que describe cómo la delincuencia organizada en Estados Unidos ha sido exitosa gracias al apoyo de políticos, burócratas y ejecutivos de transnacionales; el capitalismo fantasmal (Roy, 2014), que examina cómo las demandas del capital global han sometido a millones de personas en la India a formas brutales de depredación ambiental, explotación y racismo; las narconomics (Wainwright, 2016), que analizan desde la perspectiva económica las cadenas productivas, de distribución y venta del tráfico de drogas, que incluyen ventas por internet, diversificación de mercancías ilícitas, responsabilidad social y fusiones entre cárteles; y el capitalismo de la narcoguerra, que sugiere que los conflictos internos y la militarización se concentran en geografías importantes para proyectos de energía y extracción de recursos (Paley, 2014).

Sin embargo, ninguno de estos enfoques teóricos captura la idea de dejar morir de la forma en que lo hacen dos conceptualizaciones que ponen al centro de su ontología la violencia privada como forma de producción de capital de muerte: el capitalismo necropolítico (Banerjee, 2008) y el capitalismo gore (Valencia, 2010). El capitalismo necropolítico se refiere 
a las prácticas capitalistas o formas organizacionales de acumulación que involucran desposesión, muerte, suicidio, esclavitud, destrucción de hábitats y la organización y administración general de la violencia. Aun cuando el Estado sigue siendo clave en asegurar la acumulación originaria, en la postcolonialidad no existe una línea clara que lo divida del mercado, pues incluso las fuerzas armadas trabajan en función de garantizar el capital (Banerjee, 2008).

Por otro lado, el capitalismo gore (Valencia, 2010) funciona mejor para su aplicación en el presente artículo no sólo porque se basa en la realidad mexicana, sino porque incorpora claramente la perspectiva transfeminista, que problematiza la masculinidad hegemónica como un componente central de la violencia, lo cual resulta fundamental al analizar la crisis de derechos humanos en México. Valencia (2010) retoma el término gore de un género cinematográfico centrado en la violencia extrema para describir la etapa actual del capitalismo en el tercer mundo, donde la sangre, los cadáveres, los cuerpos mutilados y las vidas cautivas son herramientas en la reproducción del capital. Según Valencia, esta economía simultáneamente destruye órganos y produce un capital cuya reproducción se basa en la especulación de los cuerpos como mercancías y la violencia como una inversión.

Valencia caracteriza las dimensiones política, cultural, económica y de poder del capitalismo gore en términos del narco-Estado, el hiperconsumismo, el narcotráfico y la necropolítica. Dado que la necropolítica ya fue abordada antes, se abundará a continuación en los otros tres elementos.

Primero, sobre el narco-Estado, Valencia (2010) afirma que los Estados no han desaparecido en la globalización, sino que juegan el rol de garante de los mercados neoliberales a través del uso de la seguridad y la vigilancia fronteriza. Los Estados nación se han convertido en mercados-nación que operan en una red que tiene como fin la protección del 
capital. El mercado-nación más grande y exitoso del mundo es Estados Unidos, el cual difunde su cultura de consumo a través de los medios de comunicación y la publicidad, creando deseos consumistas en todas partes, incluso en lugares donde ese deseo es ilegal.

La identidad del sujeto en el mercado-nación está determinada por el consumo. El mercado-nación impone como parámetro de la identidad sociocultural el uso y consumo de marcas y logotipos, lo cual exige un alto nivel de consumo. Este hiperconsumo proporciona a cambio un statu quo que es la fuente de la identidad de mercado. Sin embargo, en el caso de México, no existe un mercado-nación sino una narco-nación, porque los cárteles de la droga controlan al Estado en vez de las empresas legales. Los cárteles del narcotráfico incorporan la violencia y las leyes del mercado en su lógica de poder.

Segundo, acerca del hiperconsumo, Valencia (2010) dice que el capitalismo no sólo es un sistema de producción, sino también una construcción cultural. Sus dinámicas crean identidades y subjetividades culturales que sostienen y generan los medios de reproducción del capital. Los rasgos culturales del capitalismo gore se construyen sobre la subversión del significado del trabajo en el postfordismo, en el cual hay una actitud de intenso desprecio hacia la cultura del trabajo y la clase trabajadora en general.

Este desprecio subvierte los procesos tradicionales de reproducción del capital y de generación de identidades sociales y culturales. En el postfordismo, el trabajo como una actividad social significativa ha sido reemplazado por el consumo, incluso en lugares extremadamente desfavorecidos y marginados. Debido a la presión generalizada para el consumo y la frustración entre los jóvenes que no pueden llegar a altos niveles de este, la economía criminal y el uso de la violencia como una herramienta de mercado se convierten en alternativas. 
Dado que el trabajo no es valorado socialmente, los jóvenes que necesitan sentirse competentes en su rol de proveedores son los que buscan trabajo en la industria gore -asesinatos, drogas, secuestro, comercio del sexo-. Esto es posible también porque existe una subversión del proyecto humanista que había prevalecido en las sociedades occidentales y occidentalizadas. El humanismo es sustituido por el consumismo. Dado que la adquisición de bienes es más valorada socialmente que la autorrealización a través del trabajo, las limitaciones éticas para participar en actividades gore se desvanecen. En el hiperconsumo la ética es redundante, es vista como la autoprotección de los perdedores. Estos cambios culturales llevan a una nueva subjetividad, que Valencia (2010) ha llamado el sujeto endriago, el cual es fundamental para explicar la subjetividad de las guerras necropolíticas.

Tercero, y último, acerca del tráfico de drogas, Valencia (2010) asegura que en el neoliberalismo existe una relación muy estrecha entre las drogas y la producción de capital debido no sólo a la globalización del hiperconsumo, sino también a la violencia económica, que incluye trabajos mal pagados, falta de oportunidades para los jóvenes, ausencia de servicios sociales, marginación social, etc.

Este tipo de violencia es clave en el surgimiento y la expansión del tráfico de drogas como empresa transnacional y como una herramienta de negocios. Como una empresa transnacional, las drogas son una mercancía de alto valor en la sociedad hiperconsumista porque funcionan como un mecanismo de autocontrol y se han convertido en una mercancía que satisface diferentes subjetividades: las personas con depresión toman Prozac, los hombres que desean aumentar su masculinidad o su virilidad toman testosterona o Viagra, las mujeres que quieren controlar su fertilidad toman la píldora anticonceptiva, etc. 
Su producción va de la mano de la investigación científica, la producción de capital y los mercados. La división entre drogas legales e ilegales -las de prescripción y las recreativas- tiene el objetivo de controlar, disciplinar y normalizar los cuerpos. La prohibición no sólo trae beneficios a las mafias, sino también a las industrias de la guerra y de las armas de Estados Unidos, esto debido a la retórica de la guerra contra las drogas. Hay, pues, un doble discurso en la política estatal que permite a los Gobiernos vincular los mercados legales (armas) y los ilegales (drogas), creando un complejo nexo entre drogas, industria militar e hiperconsumo.

La contraparte necropolítica de la gubernamentalidad neoliberal de la migración en América del Norte es el capitalismo gore, que a su vez es el imperativo económico de la necropolítica mexicana y la razón por la que las guerras necropolíticas existen, como se verá en el siguiente apartado.

\section{Migración y asilo: donde necropolítica y asilo se encuentran. Un estado del arte}

Como puede apreciarse, biopolítica y necropolítica no son opuestos, sino definitivamente constitutivos en fenómenos sociales como la migración. Explícitamente, mientras que la necropolítica produce situaciones de muerte en el primer mundo, la biopolítica es la que sirve para administrar la migración de las personas que huyen de escenarios necropolíticos que incluyen feminicidio, violencia criminal, proyectos económicos y de infraestructura, megaminería, deforestación, etcétera. La biopolítica opera a través de categorías como asilado, migrante regular o refugiado.

El asunto aquí es que la estrategia de asilo mediante el dispositivo migratorio con énfasis en el uso de la legislación internacional del derecho al asilo se utiliza para contener la amenaza cultural mexicana en tiempos de crisis de derechos 
humanos y migración forzada. El asilo es la inmunización en turno que permite contener la nueva oleada de mexicanos migrando a Estados Unidos y Canadá. El biopoder y el necropoder son constitutivos en la gestión neoliberal de las migraciones en América del Norte para sostener un statu $q u o$ en el que la mayoría blanca y masculina mantiene su dominación y al mismo tiempo garantiza la precariedad social de los mexicanos.

El estudio del biopoder es común en Europa, Reino Unido, Australia y Sudamérica para analizar la migración desde la perspectiva de la seguridad (Bigo, 2002; Ceyhan y Tsoukala, 2002; Darling, 2009; Edkins y Pin-Fat, 2005; Muller, 2004; Owens, 2009; Tyler, 2010; Zylinska, 2004) y como un problema a controlar con fines racistas (Bastos, 2008; Bolaños, 2013; FitzGerald, 2010; Kalm, 2005; Kelly, 2004; Kunz, 2008; Vaccotti, s/f; Yuing, 2011).

En México, sin embargo, su uso es reciente y no tiene la amplitud que ha alcanzado en otros países de América Latina como Chile, Argentina y Brasil, aunque se ha logrado establecer un pequeño núcleo de académicos con intereses en la producción de conocimiento sobre biopolítica y necropolítica situado. ${ }^{2}$ En México, la biopolítica se estudia en el ámbito de políticas de asistencia a la pobreza (Arteaga Botello y Valdés Figueroa, 2010), espacio público y democracia (Gallegos, 2013) y ley (Gutiérrez Zúñiga, 2014; Pereyra Tissera, 2011).

En el tema de la migración, en México el estudio del biopoder es limitado debido al apabullante predominio de la perspectiva hegemónica concentrada en las redes transna-

2. En cuanto a la biopolítica, este núcleo se aglutina en el capítulo mexicano de la Red de Biopolítica, que es una iniciativa chileno-australiana liderada por el chileno Miguel Vatter en la University of New South Wales (ver: http://www. biopolitica.unsw.edu.au/es). También se encuentra el Seminario de Biopolítica y Necropolítica Situadas CISAN-UACM, que aglutina a académicas y estudiantes interesadas en la producción conceptual de una biopolítica y una necropolítica propiamente mexicanas. 
cionales, las remesas y la religión y la cultura, sin análisis sistemático de género ni de las expresiones de autonomía o resistencia.

En los marcos foucaultianos, encontramos estudios que problematizan la frontera norte de México y el trato de Estados Unidos a ciudadanos mexicanos. Algunos de estos estudios están basados en la perspectiva de la gubernamentalidad y analizan diferentes dispositivos biopolíticos para la gestión de la vida en las migraciones, como los de salud (Farfán, Vizcarra, y González, 2012; Parrini, 2015) y los de detención (Moreno Hernández, 2014). También existen los trabajos de subjetivación racializada a través de biopolíticas migratorias (Bolaños, 2009, 2013) y seguridad y migración (Bolaños y Levine, 2014).

En México, el estudio del necropoder tiene influencia a través del pensamiento decolonial y feminista, y dicha influencia se debe a la siempre creciente contabilidad de feminicidios, ejecuciones y desapariciones forzadas que afectan a las poblaciones de migrantes, niños, mujeres indígenas y mujeres de áreas urbanas con precariedad económica y social. A nivel teórico, el estudio del necropoder ha sido reinterpretado y ampliado por Valencia (2010), y a nivel empírico ha sido útil para estudiar lo que Antonio Fuentes denomina nuevas violencias, entre las que identifica la narcoguerra, los linchamientos y las pandillas, cuyas dinámicas causales ve en el colonialismo y la explotación laboral del capitalismo a niveles de desposesión (Fuentes Díaz, 2012).

A nivel de la opinión pública, el término necropoder se popularizó con el libro de investigación periodística de Diego Enrique Osorno titulado La guerra de los Zetas. Un viaje por la frontera de la necropolítica. Hoy es común ver el uso estrictamente semántico de la necropolítica (política de muerte) en noticias relativas a violencia criminal de medios 
de comunicación populares en las redes-Sinembargo, Contralinea, SDPNoticias, MVS, Rebelión, Publimetro-.

En la perspectiva necropolítica, la migración se ve en el contexto de la violencia criminal-estatal, particularmente respecto a la gestión de la muerte de migrantes centroamericanos y sus dispositivos más importantes como el ferrocarril la Bestia y los centros de detención, así como respecto a los sujetos violentos que son conducidos para la destrucción de cuerpos (maras, sicarios, cárteles, betas). La muerte de migrantes es una gran preocupación académica hasta para lo hegemónico, pues debido a la popularidad del término, incluso algunos autores del canon están empezando a hacer un uso rudimentario, casi semántico en vez de analítico, del marco conceptual del necropoder (Márquez Covarrubias, 2015). Un uso más riguroso del término se da para analizar el uso de masacres, ejecuciones, desapariciones forzadas, violaciones sexuales, feminicidios de migrantes centroamericanos y el desplazamiento forzado internacional de mujeres y hombres en el contexto de la guerra contra el narco y la violencia sexual, todo esto como tecnologías del necropoder (Estévez, 2012a, 2012b, 2013a, 2013b, 2015a, 2015b).

\section{Conclusiones}

Como puede apreciarse, los estudios del biopoder y los del necropoder en la gestión migratoria tienen características que los distinguen entre sí. Es común, pues, que en los estudios del biopoder y el necropoder el enfoque esté en la regulación de la vida racializada para dejar morir a los migrantes y preservar la vida de las mayorías a través de dispositivos y leyes que producen subjetividades determinadas. Las investigaciones del necropoder, en específico, examinan las expresiones de violencia espectacular y masiva que destruyen o mercantilizan cuerpos. De esta forma, el biopoder tiene expresiones jurídicas pero el necropoder no, 
porque se asume que las expresiones necropolíticas ocurren al margen de la ley -a través del Estado de excepción-, y no dentro de ella.

La sugerencia aquí es que eso es una falacia. El biopoder y el necropoder son conceptos constitutivos, porque en casos como la migración, el uso de la ley de asilo como biopolítica migratoria es posible en la medida en que existe una necropolítica que expulsa a las personas de su país.

En su parte constitutiva, existen dispositivos legales biopolíticos que son funcionales a la gestión de la vida de solicitantes de asilo en Estados Unidos a través de leyes como la de asilo, los centros de detención de asilados y el funcionamiento administrativo de la justicia migratoria a través de burócratas, jueces potencialmente racistas y jurisprudencias no ancladas en derechos constitucionales. Por otro lado, están los dispositivos necropolíticos ampliamente conocidos, como masacres, ejecuciones, feminicidios, linchamientos, secuestro masivo y explotación y esclavitud sexuales y laborales.

También, están las acciones e inacciones legales que administran la antesala de la muerte o sus productos relacionados, como el sufrimiento. Las acciones legales incluyen gestiones tales como las reformas que criminalizan la protesta (tipificación de terrorismo en el Código Penal federal), reglamentan el Estado de excepción (reformas a la ley reglamentaria del artículo 29 constitucional), hacen legales los cateos militares en delitos vinculados al narcotráfico (reformas al Código de Justicia Militar), legalizan el uso de la fuerza contra manifestantes (las llamadas Ley Atenco, en el Estado de México, y Ley Bala, en Puebla) y legitiman la acción estatal en violencia feminicida sin abordar las causas y la impunidad (alertas de género).

Las inacciones, por su parte, se refieren a la impunidad estructural, la corrupción sistemática a todos los niveles de Gobierno y la misógina institucional en los órganos de 
justicia. Estas inacciones se hacen tangibles a través de subjetividades y tecnologías paralegales y extralegales como los policías y militares sicarios, la disponibilidad indiscriminada de armas, la existencia de casas de seguridad clandestinas, el uso de instituciones del Estado por parte de la delincuencia organizada (por ejemplo, los centros de aseguramiento de migrantes) y los sujetos misóginos violentos protegidos por el pacto misógino o patriarcal (leyes discriminatorias, autoridades judiciales violentas).

Bibliografía

Agamben, G. (1998). Homo sacer. El poder soberano y la nuda vida. España: Pre-textos.

Agamben, G. (200I). Medios sin fin. España: Pre-textos.

Agamben, G. (2004). El estado de excepción. Valencia: Pretextos.

Agamben, G. (2009). What Is an Apparatus? And Other Essays. California: Stanford University Press.

Arteaga Botello, N., y Valdés Figueroa, J. (2010). "Contextos socioculturales de los feminicidios en el Estado de México: nuevas subjetividades femeninas". Revista mexicana de sociología, 72(I), 5-35.

Banerjee, B. (2008). “Necrocapitalism”. Organization Studies, 29(I2), I54I-I563.

Bastos, C. (2008). "Migrants, Settlers and Colonists: The Biopolitics of Displaced Bodies". International Migration, 46(5), 27-54.

Bauman, Z.(200I)."Wars of the Globalization Era”. European Journal of Social Theory, 4(I), II-28.

Bigo, D. (2002). "Security and Immigration:Toward a Critique of the Governmentality of Unease". Alternatives: Global, Local, Political, 27(I), 63-92.

Bolaños, B. (2009). “Migración, derecho consular y justicia global”. Isonomía: revista de teoría y filosofía del derecho, (30), 7-30.

\section{8}


Bolaños, B. (20। 3). Esclavos, migrantes y narcos. Acontecimiento Bibliografía y biopolítica en América del Norte. Mexico: UAM-I, Juan Pablos Editores.

Bolaños, B., y Levine, E. (20I4). "Biopolítica y bioeconomía de la reforma migratoria en Estados Unidos". Carta económica regional, 26(I |4).

Butler, J. (2006). Precarious life: The powers of mourning and violence. Londres:Verso.

Campesi, G. (20I2). “Migraciones, seguridad y confines en la teoría social contemporánea”. Crítica penal y poder, (3), I-66.

Castro, E. (2004). El vocabulario de Michel Foucault. Un recorrido alfabético por sus temas, conceptos y autores. Bernal: Universidad Nacional de Quilmes.

Ceyhan, A., y Tsoukala, A. (2002). "The Securitization of Migration in Western Societies:Ambivalent Discourses and Policies". Alternatives: Global, Local, Political, 27(I), 21-39.

Darling,J. (2009)."Becoming bare life: Asylum, hospitality, and the politics of encampment". Environment and Planning D: Society and Space, 27, 649-665.

Edkins, J., y Pin-Fat, V. (2005). "Through the Wire: Relations of Power and Relations of Violence". Millenium: Journal of International Studies, 34( I), I -24.

Esposito, R. (2005). Immunitas: protección y negación de la vida. Buenos Aires:Amorrortu.

Estévez, A. (2012a)."Asilo y derechos humanos en Estados Unidos y Canadá. Cuestionamientos a Giorgio Agamben”. Norteamérica, 7(I), 183-206.

Estévez, A. (20I2b). "La violencia en México como crisis de derechos humanos: las dinámicas violatorias de un conflicto inédito". Contemporánea, 2(I), 2I-44.

Estévez, A. (20 I 3a).“The Biopolitics of Asylum Law In Texas: The Case of Mexicans Fleeing DrugViolence in Juárez”. Norteamérica, 8(número especial), 55-8I. 
Bibliografía
Estévez, A. (20|3b). "The Politics of Death in Mexico: Dislocating Human Rights and Asylum Law Through Hybrid Agents". Glocalism: Journal of Culture, Politics and Innovation, I ( I), I-28.

Estévez,A. (2015a). "The Endriago subject and the dislocation of state attribution in human rights discourse:The case of Mexican asylum claims in Canada". Third World Quarterly, 36(5).

Estévez, A. (20I5b). "La presunta falsedad de los casos de asilo de mexicanos en Canadá: un análisis necropolítico". Con-temporánea.Toda la historia en el presente, (4). Recuperado de: http://con-temporanea.inah.gob.mx/ del_oficio/ariadna_estevez_num4

Farfán, F.,Vizcarra, I.,y González, N. (20I2)."Políticas de salud. Estrategia biopolítica para controlar a los migrantes mexicanos en Estados Unidos”. Migración y desarrollo. Red Internacional de Migración y Desarrollo, I0(19), 3-32. FitzGerald, S. A. (20I0). "Biopolitics and the regulation of vulnerability:The case of the female trafficked migrant". International Journal of Law in Context, 6(3), 277-294.

Foucault, M. (1 988). The Care of the Self.The History of Sexuality. Londres:Allen Lane The Penguin Press.

Foucault, M. (1997). Ethics: Subjectivity and Truth. Vol. I. Nueva York: The New Press New York.

Foucault, M. (2000). Power. Vol. III. Nueva York:The New Press. Foucault, M. (2004). The Birth of Biopolitics. Nueva York: Picador-Palgrave Macmillan.

Foucault, M. (2006a). Defender la sociedad. México: Fondo de Cultura Económica.

Foucault, M. (2006b). Seguridad, territorio, población. México: Fondo de Cultura Económica.

Foucault, M., Senellart, M., y Davidson, A. I. (2007). Security, territory, population: Lectures at the College de France, 1977-78. Basingstoke: Palgrave Macmillan. 
Fuentes Díaz,A. (20I2). “Necropolítica y excepción. Notas Bibliografía sobre Gobierno, violencia y subjetividad en México y Centroamérica", en A. Fuentes Díaz (ed.), Necropolítica, violencia y excepción en América Latina (pp. 33-50). Puebla: BUAP.

Gallegos, E. E. (2013).“Espacio público, temporalidad biopolítica e inmunidad”, en G. Pérez (ed.), Temas selectos de la teoría política contemporánea (pp. 399-426). México: UAM-Cuajimalpa.

Gržinić, M. (2010). "From Biopolitics to Necropolitics and the Institution of Contemporary Art". Pavilion. Journal for Politics and Culture, (14), 9-93.

Gržinić, M., y Tatlić, Š. (20I4). Necropolitics, Racialization, and Global Capitalism. Historicization of Biopolitics and Forensics of Politics, Art, and Life. Lanham: Lexington Books.

Guendel, L. (2009). Políticas públicas y derechos humanos. Principios, enfoques e instrumentos. Madrid: Centro de Estudios de Iberoamérica, Comunidad de Madrid.

Gutiérrez Zúñiga, M. (20/4). "Infancia y biopolítica en el México contemporáneo. Del amparo de la ley al abandono. Performatividades y paradojas del discurso jurídico de protección a la infancia, en el contexto de la experiencia de una niña”. Diálogos sobre educación, 5(8), 31.

Harman, C. (2009). Zombie capitalism: Global crisis and the relevance of Marx. Londres: Bookmarks.

Harvey, D. (2004). “El nuevo imperialismo: acumulación por desposesión”. Socialist register, 2004, 99-129.

Henao Castro, A. F. (2016). "From the 'Bio' to the 'Necro'. The Human at the Border", en S. E.Wilmer,y A. Zukauskaite (eds.), Resisting biopolitics: Philosophical, political, and performative strategies (pp. 237-253). Nueva York: Routledge.

Juniper, J. (2006). "Homo Sacer and Biopower: Defending Foucault against Agamben's ‘Oscillating' Critique”. Tra- 
Bibliografía bajo presentado en la Australasian Political Studies Association Conference. University of New Castle, Australia. Kalm, S. (2005). “Towards global migration management? -A biopolitical approach”. Trabajo pesentado en ISA 2005. Honolulú, Hawái.

Kelly, M. (2004). "Racism, Nationalism and Biopolitics: Foucault's Society Must Be Defended, 2003”. Cintretemps, (4), 58-70.

Kunz, R. (2008). "Mobilising diasporas: A governmentality analysis of the case of Mexico". Workin Paper Series, Glocal Governance and Democracy, (03). Recuperado de: http://citeseerx.ist.psu.edu/viewdoc/download?doi= 10 . I. I.6 I 3.3099\&rep=rep I \& type $=$ pdf

Laclau, E. (2008). “¿Vida nuda o indeterminación social?”, en E. Laclau (ed.), Debates y combates. Por un nuevo horizonte de la política (pp. I07-I23).Argentina: Fondo de Cultura Económica.

Márquez Covarrubias, H. (20I5). "Espectros del neoliberalismo. Economía de traspatio y necropolítica en México". Estudios críticos del desarrollo, 5(9), 87-I39. Recuperado de: http://www.estudiosdeldesarrollo.mx/ critical/rev9/3.pdf

Mbembe,A. (20I I). Necropolítica. España: Melusina.

Moreno Hernández, H. C. (20|4). “Desciudadanización y estado de excepción”. Andamios, I I (24), I25-I48.

Muller, B. (2004). “Globalization, Security, Paradox:Towards a Refugee Biopolitics". Canada's periodical on refugees, 22(I), 57.

Owens, P. (2009). “Reclaiming 'Bare Life'?:Against Agamben on refugees”. International Relations, 23(4), 567-582.

Paley, D. (20I4). Drug War Capitalism. Oakland:AK Press.

Parrini, R. (20I5). "Biopolíticas del abandono: migración y dispositivos médicos en la frontera sur de México". Nómadas. Universidad Central de Colombia, (42), I I I-I 27. 
Pereyra Tissera, G. D. (20II). "Deconstrucción y biopolítica. El problema de la ley y la violencia en Derrida y Agamben". Revista mexicana de ciencias políticas y sociales, 56(2I2), 3I-54.

Round, J., y Kuznetsova, I. (2016). "Necropolitics and the Migrant as a Political Subject of Disgust:The Precarious Everyday of Russia's Labour Migrants". Critical Sociology, $42(3), \mathrm{I}-18$.

Roy, A. (20 I4). Capitalism:A ghost story. Chicago: Haymarket Books.

Tyler, I. (2010). "Designed to fail: A biopolitics of British citizenship". Citizenship Studies, I4(I), 6I-74.

Vaccotti, L. (s/f). Biopolíticas de la inmigración y derechos humanos de los inmigrantes en Argentina. Recuperado de: http://webiigg.sociales.uba.ar/pobmigra/archivos/ vaccotti_biopoliticas.pdf

Valencia, S. (20I0). Capitalismo gore. España: Melusina.

Valverde Gefaell, C. (2016). De la necropolítica neoliberal, a la empatía radical. Violencia discreta, cuerpos excluidos y repolitización. Madrid: Icaria.

Wainwright, T. (20 I6). Narconomics: How to run a drug cartel. Nueva York: PublicAffairs.

Woodiwiss, M. (2005). Gangster capitalism:The United States and the global rise of organized crime. Londres: Constable.

Yuing,T. (20I I)."Migraciones y administración de la vida en el mundo”. Psicoperspectivas. Individuo y sociedad, IO(I), 6-20.

Zylinska, J. (2004). "The Universal Acts. Judith Butler and the biopolitics of immigration”. Cultural Studies, I8(4), 523-537. 